\title{
ASSESSMENT OF LUNG FUNCTION STATUS OF WORKERS AT A TRANSFORMER MANUFACTURING PLANT IN SELANGOR, MALAYSIA
}

\author{
Syazawani Shamsudin ${ }^{1}$, Nurul Farahana Kamaludin ${ }^{1}$, Nur Syuhadah Khairiri ${ }^{1}$, Normah Awang ${ }^{1}$ and Anuar \\ Ithnin ${ }^{1}$
}

${ }^{1}$ Center for Toxicology and Health Risk Studies (CORE), Faculty of Health Sciences, Universiti Kebangsaan Malaysia, Jalan Raja Muda Abdul Aziz, 50300 Kuala Lumpur.

Corresponding author: Nurul Farahana Kamaludin

Email: nurulfarahana@ukm.edu.my

\begin{abstract}
Transformer manufacturing industry uses volatile organic compounds (VOCs) containing materials such as varnish which can cause adverse health effects to human. Exposure to a high level of VOCs could disrupt the normal functions of a human lung. Therefore, this study was conducted to evaluate the status of lung functions of the workers exposed to VOCs at a transformer manufacturing plant in Selangor. The volatile organic compounds (VOCs) concentration in the office and production area was measured using direct-reading method and 60 subjects were selected to undergo the lung function test. The FVC and FEV 1 values showed significant difference $(p<0.05)$ between the exposed group and the

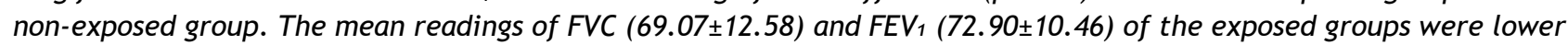
than the non-exposed group, which were $81.47 \pm 9.78$ and $84.23 \pm 9.07$, respectively. In contrast to the FEV $1 / F V C$ parameters, the non-exposed group (102.93 \pm 7.17$)$ showed lower mean values than the exposed group (105.90 \pm 8.98$)$. Besides that, the nasal symptoms showed significant differences $(p<0.05)$ between the exposed and non-exposed group. The demographic data of the exposed group showed no association with the lung function status of the exposed group workers. However, the lung functions of the exposed group were influenced by the concentration of VOCs in the production area. High concentration of VOCs may cause detrimental effects on the lung functions. Therefore, management or employers in the industry should always be aware of the effects of VOCs, and take appropriate steps to ensure the safety and welfare of the employees.
\end{abstract}

Keywords: Lung function, Volatile organic compounds (VOCs), Varnish, Transformer, Industry

\section{INTRODUCTION}

Manufacturing industry is an industry involved with process modification of goods or materials to produce new products ${ }^{1}$. Around $15 \%$ of 750,00 workers in the manufacturing sectors have been diagnosed with asthma which is caused by the working environment ${ }^{2}$ and $21.5 \%$ of workers who have respiratory problem of asthma show an increase in the severity of asthma also caused by the working environment ${ }^{3}$. The transformer manufacturing industry includes some important work processes such as wiring, winding, coring and impregnation. Workers of the transformer manufacturing plant especially in the production line are exposed to volatile organic compounds (VOCs). They use varnish to insulate the transformers to increase dielectrics strength, aid the heat release from the coils, and protect the wire from damage during the exchange of electric flow $^{4}$. It turns out that varnish is the main source of VOCs produced inside the buildings area. Building materials, packaging materials, paints, and solvents are also the sources of VOCs released in the air ${ }^{5}$.

Exposure to VOCs is associated with respiratory disorders like asthma, bronchitis and chronic obstructive pulmonary disease (COPD) $)^{6,7}$. COPD occurs due to the limitation of the airflow caused by the inflammation on the lungs resulting from the inhalation of harmful gas and particles ${ }^{8}$. The respiratory system is the main route of VOCs exposure through inhalation ${ }^{9}$ and the exposure to the VOCs occurs from the working activities in the workplace either indoor or outdoor environment ${ }^{10}$. Long-term exposure towards pollutants in the workplace can cause changes to the lung functions in human ${ }^{11}$. The hazardous indoor air pollutants, especially carcinogenic VOCs such as benzene and toluene can cause cancer ${ }^{12}$. The workers who are exposed to the VOCs in the transformer manufacturing industry may experience the harmful effects on their respiratory health.

Malaysia is a developing country whereby industries are growing and expanding, including transformer manufacturing plant. Industries are common main contributors of chemical air pollutants that can be harmful to humans, but only a few studies address the effects of the chemical air pollutants to the pulmonary functions especially in Malaysia. Thus, the purpose of this study was to assess the association of VOCs level and lung function status of the workers exposed to VOCs at the transformer manufacturing plant. The result of this study can 
be used by the management to take the control measures. As stipulated in the Occupational Safety and Health Act 1994 (Act 514), it is important for both employees and employers to practice safety and health in a workplace to maintain the safety and health of the workers.

\section{METHODS}

\section{Study subject}

This was a cross-sectional study. A total of 60 nonasthmatic workers who worked more than 3 months was chosen for this study as the subjects. The subjects were divided into two groups: exposed $(\mathrm{N}=30)$ and non-exposed group $(\mathrm{N}=30)$. Thirty workers were exposed to VOCs in the production area and 30 non-exposed subjects worked in the office of the transformer manufacturing plant. All subjects were working 8 hours per day and 5 days per week. This study was conducted after obtaining an approval from the Research and Ethics Committee Universiti Kebangsaan Malaysia (UKM) Medical Centre, Malaysia (UKM reference number PPI/111/8/JEP2019-039 dated 25 January 2019) and informed consent from the subjects.

\section{Ambient level of VOCs}

The VOCs concentrations were measured in the ambient indoor air. Air sampling was carried out to determine the VOCs concentrations by using a calibrated portable sensor (Aeroqual series 500) in both office and production area. There were 5 sampling points in the office area. These sampling points in the office were identified by each department as all worked in the same area with an open space (S1- quality control and engineering, S2- marketing, S3- finance, S4human resources, and S5- photocopier and printers area). As for the production area, there were 8 sampling points selected based on the main workstation: S1, S2- impregnation (near varnish tank and oven), S3 and S4-finishing (painting the transformer and quality check), S5production of small transformer, S6- coring and winding of domestic transformer, S7-winding of large transformer, and S8-preparing area. The air sampling was conducted during 8 working hours, whereby the time should be evenly distributed into 4 time-slots. Then, the measurement was taken 3 times in 10-minute intervals at each sampling point.

\section{Questionnaire survey}

Each subject from both groups was interviewed and given a questionnaire adapted from the American Thoracic Society (ATS) ${ }^{13}$. The questionnaire was used to collect the sociodemographic data of the workers to be associated with the lung functions test results. There were three sub-sections in the questionnaire: sociodemographic information, health status of the subject (respiratory symptoms) and working environment (the ventilation system, personal protective equipment (PPE) in the workplace).

\section{Lung function test}

The lung function test (LFT) was conducted on both exposed group $(n=30)$ and non-exposed group $(n=30)$ following the ATS guidelines ${ }^{13,14}$. The parameter of tests; forced vital capacity (FVC), forced expiratory volume in one second $\left(\mathrm{FEV}_{1}\right)$ and $\mathrm{FEV}_{1} / \mathrm{FVC}$ ratio were recorded by using calibrated Cosmed Pony FX Desktop Spirometer. The LFT was conducted during working hours (0800 to 1700). The accurate techniques of performing the LFT were demonstrated to the subjects before starting the test. Each subject was required to sit with a straight back and shoulder. After that, the subject must take a deep breath before doing the test. Each subject was given three trials and the best results were selected as the final results for the statistical analysis.

\section{Statistical analysis}

The statistical analysis was performed using Statistical Package of Social Sciences (SPSS) version 25.0. A normality test was done to assess the distribution of the collected data and whether the data were normally distibuted. Sociodemographic data were presented descriptively while VOCs concentrations and LFT parameters were presented as mean \pm standard deviation. Independent t-test was used to compare lung function parameter between exposed and nonexposed groups. The association between demographic factor and lung function status of exposed workers was tested by Chi-Square or Fisher's Exact test. Pearson correlation statistical analysis was used to correlate the relationship between VOCs concentration and lung function parameter of exposed workers. A $p$-value $<0.05$ was considered sigificant.

\section{RESULTS}

\section{Concentration of VOCs}

Table 1 shows the level of VOCs concentration in the office and production area. All the concentration of VOCs in the office area was less than $3 \mathrm{ppm}$, not exceeding the acceptable limit set by the Industrial Code of Practice on Indoor Air Quality (ICOP) ${ }^{15}$. The highest concentration of VOCs in the office area was at sampling point 2 , which was $1.72 \pm 0.70 \mathrm{ppm}$. Meanwhile, the VOCs concentrations in the production area were higher (>3 ppm) than the office area except for the sampling point 8 , which was $2.83 \pm 0.22 \mathrm{ppm}$. The highest concentration of VOCs at the production area was at sampling point 1 , followed by sampling point 6 which were $5.55 \pm 0.09 \mathrm{ppm}$ and $5.43 \pm 0.32 \mathrm{ppm}$, respectively. 
Table 1: VOCs concentration at office and production area

\begin{tabular}{|c|c|c|c|}
\hline Sampling area & Sampling points & $\begin{array}{l}\text { VOCs concentration } \\
(\mathrm{ppm})\end{array}$ & $\begin{array}{c}\text { Average concentration } \\
(\mathrm{ppm})\end{array}$ \\
\hline \multirow[t]{5}{*}{ Office } & 1 & $1.29 \pm 0.22$ & $0.84 \pm 0.67$ \\
\hline & 2 & $1.72 \pm 0.70$ & \\
\hline & 3 & $0.74 \pm 0.04$ & \\
\hline & 4 & $0.25 \pm 0.14$ & \\
\hline & 5 & $0.18 \pm 0.10$ & \\
\hline \multirow[t]{8}{*}{ Production } & 1 & $5.55 \pm 0.09$ & $4.45 \pm 0.32$ \\
\hline & 2 & $4.60 \pm 0.35$ & \\
\hline & 3 & $4.57 \pm 0.27$ & \\
\hline & 4 & $4.92 \pm 0.16$ & \\
\hline & 5 & $4.11 \pm 0.16$ & \\
\hline & 6 & $5.43 \pm 0.32$ & \\
\hline & 7 & $3.62 \pm 0.16$ & \\
\hline & 8 & $2.83 \pm 0.22$ & \\
\hline
\end{tabular}

Table 2: Demographic data of exposed and non-exposed group $(n=60)$.

\begin{tabular}{lcc}
\hline Demographic data & $\begin{array}{c}\text { Exposed group } \\
\text { Total subject, }(\mathbf{n}=30) \\
\mathrm{n}(\%)\end{array}$ & $\begin{array}{c}\text { Non-exposed group } \\
\text { Total subject, }(\mathbf{n}=30) \\
\mathrm{n}(\%)\end{array}$ \\
\hline Gender & $19(63.3)$ & $13(43.3)$ \\
Male & $11(36.7)$ & $17(56.7)$ \\
Female & & \\
Race & $18(60.0)$ & $22(73.3)$ \\
Malay & $11(36.7)$ & $4(13.3)$ \\
Indian & $1(3.3)$ & $3(10.0)$ \\
Chinese & 0 & $1(3.3)$ \\
Others & & \\
Smoking Status & $7(23.3)$ & $7(23.3)$ \\
Smoker & $23(76.7)$ & $23(76.7)$ \\
Non-smoker & & \\
Working years & $11(36.7)$ & $17(56.7)$ \\
$<20$ years & $19(63.3)$ & $13(43.3)$ \\
$\geq 20$ years & & \\
BMl & $16(53.3)$ & $17(56.7)$ \\
$<25.0$ (Normal) & $14(46.7)$ & $13(43.3)$ \\
$\geq 25.0$ (Overweight) & & \\
\hline Age (years) & $2(6.7)$ & $5(16.7)$ \\
$<30$ & $20(66.7)$ & $5(16.7)$ \\
30 - 50 & $8(26.7)$ & \\
$>50$ & & \\
\hline
\end{tabular}




\section{Socio-demographic characteristic}

Table 2 presents the demographic data of the subjects of both exposed group $(n=30)$ and nonexposed group $(n=30)$. There were more male workers $(63.3 \%)$ in the exposed group compared to non-exposed group, which majority was female $(56.7 \%)$. Most of the subjects from both group were Malay and they had a normal body mass index (BMI). As for the smoking status, both group showed few workers who smoked (23.3\%).

\section{Lung Function Findings}

The description of the average estimation of lung function parameters (FVC, $\mathrm{FEV}_{1}$ and $\mathrm{FEV}_{1} / \mathrm{FVC}$ ) for both exposed and non-exposed group was shown in Table 3. Based on the results, the mean of FVC and $\mathrm{FEV}_{1}$ of the exposed group was lower than the non-exposed group. The $\mathrm{FEV}_{1} / \mathrm{FVC}$ parameter showed higher percentages in the

exposed group than the non-exposed group, with $105.90 \pm 8.98$ and $102.93 \pm 7.17$, respectively. Independent $\mathrm{t}$-test analysis showed that there were significant differences $(p<0.05)$ in the FVC and $\mathrm{FEV}_{1}$ in the exposed and non-exposed group. The exposed group showed a decline in the lung functions.

Table 3: Lung function parameters (FVC, $\mathrm{FEV}_{1}$ and $\left.\mathrm{FEV}_{1} / \mathrm{FVC}\right)$ of exposed and non-exposed groups.

\begin{tabular}{|c|c|c|c|}
\hline Parameter & $\begin{array}{l}\text { Exposed group } \\
\text { (mean } \pm \text { stdev) }\end{array}$ & $\begin{array}{l}\text { Non-exposed group } \\
\text { (mean } \pm \text { stdev) }\end{array}$ & $p$-value \\
\hline FVC (\%) & $69.07 \pm 12.58$ & $81.47 \pm 9.78$ & $0.000^{*}$ \\
\hline $\mathrm{FEV}_{1}(\%)$ & $72.90 \pm 10.46$ & $84.23 \pm 9.07$ & $0.000^{*}$ \\
\hline $\mathrm{FEV}_{1} / \mathrm{FVC}(\%)$ & $105.90 \pm 8.98$ & $102.93 \pm 7.17$ & 0.163 \\
\hline
\end{tabular}

*significance value is $p<0.05$

According to the Global Initiative Chronic Obstructive Lung Disease (GOLD) ${ }^{16}$, the normal status indicates that the subject has normal spirometry reading while abnormal status indicates that the subject is in either restrictive or obstructive condition. The descriptive analysis showed $80.0 \%$ of the exposed group had abnormal status of lung functions and another $20 \%$ of them had normal. As for the non-exposed group, 56.7\% of the subjects had normal lung functions and 43.3\% had abnormal status.
The respiratory symptoms among exposed workers and non-exposed workers were presented in Table 4. The association was conducted between the lung function status and demographic data of the workers. Statistical results showed that cough and dyspnea did not have a significant association in either exposed or non-exposed group. Both groups showed similar patterns on the respiratory symptoms of cough and dyspnea. However, nasal symptoms showed a statistically significant association between both groups.

Table 4: The respiratory symptoms among exposed and non-exposed groups.

\begin{tabular}{lccc}
\hline Respiratory symptoms & $\begin{array}{c}\text { Exposed group } \\
(\mathbf{n}=30) \\
\mathrm{n}(\%)\end{array}$ & $\begin{array}{c}\text { Non-exposed group } \\
(\mathbf{n}=30) \\
\mathbf{n}(\%)\end{array}$ & $p$-value \\
\hline Cough & $7(11.7)$ & $4(6.7)$ & \\
Yes & $23(38.3)$ & $26(43.4)$ & 0.317 \\
No & $2(3.3)$ & $2(3.3)$ & \\
Dyspnea & $28(46.7)$ & $28(46.7)$ & \\
Yes & & $28(46.7)$ & \\
No & $21(35.0)$ & $2(3.3)$ & $0.042^{*}$ \\
Nasal symptoms & $9(15.0)$ & & \\
Yes & & & \\
No & & &
\end{tabular}

*significant value is $p<0.05$

Table 5 showed the association of demographic data with lung function status of the exposed group. Working years, smoking status and BMI of the workers did not show a significant association $(p>0.05)$ with respect to the lung function status of the exposed group. Therefore, working years, smoking habits and BMI has no direct effect on the lung conditions of the exposed workers. 
Table 5: Association of demographic data with lung function status of exposed group.

\begin{tabular}{|c|c|c|c|}
\hline \multirow{2}{*}{$\begin{array}{l}\text { Socio-demographic } \\
\text { factors }\end{array}$} & \multicolumn{2}{|c|}{ Lung function test status } & \multirow[t]{2}{*}{$p$-value } \\
\hline & Normal $\mathrm{n}(\%)$ & Abnormal n(\%) & \\
\hline \multicolumn{4}{|l|}{ Working years } \\
\hline$<20$ years & $3(10.0)$ & $7(23.3)$ & \multirow[t]{2}{*}{0.372} \\
\hline $\begin{array}{l}\geq 20 \text { years } \\
\text { Smoking status }\end{array}$ & $3(10.0)$ & 17(56.7) & \\
\hline Yes & $3(10.0)$ & $4(13.3)$ & \multirow[t]{2}{*}{0.120} \\
\hline No & $3(10.0)$ & $20(66.7)$ & \\
\hline \multicolumn{4}{|l|}{ BMI } \\
\hline <25.0 (normal) & $5(16.7)$ & 11(36.7) & \multirow[t]{2}{*}{0.175} \\
\hline$\geq 25.0$ (obesity) & $1(3.3)$ & $13(43.3)$ & \\
\hline
\end{tabular}

${ }^{*}$ significant value is $p<0.05$

The relationship between the parameter of lung function (FVC, FEV ${ }_{1}$ and $\mathrm{FEV}_{1} / \mathrm{FVC}$ ) of the exposed group and VOCs concentration at the production area was tabulated in Table 6 . The results showed that there were negative and medium associations of FVC and FEV 1 with VOCs concentration, $r=$ 0.435 and $r=-0.431$, respectively. However, the $\mathrm{FEV}_{1} / \mathrm{FVC}$ parameter showed positive and medium correlation with the concentration of VOCs, obtaining $r=0.622$. There were no significant differences between the lung function parameters and the VOCs concentrations in the production area.

Table 6: Association of VOCs concentration with lung function parameter of exposed group.

\begin{tabular}{ccc}
\hline Parameter of LFT & \multicolumn{2}{c}{ VOCS concentration $(\mathrm{n}=8)$} \\
\cline { 2 - 3 } & Pearson correlation & $p$-value \\
\hline FVC (\%) & -0.435 & 0.282 \\
FEV (\%) & -0.431 & 0.286 \\
FEV/FVC & 0.622 & 0.100
\end{tabular}

*significant value is $p<0.05$

\section{DISCUSSION}

In the office area, all the concentration of VOCs was below $3 \mathrm{ppm}$ and they did not exceed the acceptable limit set by ICOP' ${ }^{15}$. The VOCS concentrations in the office area may be influenced by the indoor sources. Building materials such as paint, solvents, air fresheners and furniture have been shown to be the largest contributor to VOCs in an indoor environment ${ }^{17}$. Generally, the VOCs concentrations in the production area were significantly higher compared to the office area. This finding was reliable as the main source of the VOCs emission, which was varnish, was in the production area. Varnish contains high VOCs components that will increase the VOCs exposure especially if less ventilation is added in the workplace ${ }^{18}$. In addition to that, the increase of VOCs concentration is inversely related with the movement of the air in the buildings ${ }^{19}$. This indicates that workers who work within the production area are exposed to high level of VOCs concentrations. Apparently, the higher exposure to this air pollutant might deteriorate the respiratory health and cause adverse health effects such as dizziness, nausea, mucosal irritation and inflammation ${ }^{20,21 .}$
The mean values of lung function parameters (FVC and $\mathrm{FEV}_{1}$ ) showed significant differences between the exposed and non-exposed groups. The exposed group showing a decline in lung function could be attributed to the higher VOCs concentration in the production area. Workers exposed to toxic pollutants such VOCs potentially experience adverse effects on their respiratory health ${ }^{22}$. Irritation on the airways of the lungs caused by the release of the chemicals at work can lead to respiratory problems ${ }^{23}$. Our findings were parallel with several studies. Studies by Mehta et al. ${ }^{24}$ and Prasetyo et al. ${ }^{25}$ showed significant decrease of lung function parameters among petrol pump workers and gasoline station workers due to the exposure to VOCs. According to the standard guideline by GOLD ${ }^{16}$, the exposed group suffers a restrictive condition when the parameter of $\mathrm{FVC}$ and $\mathrm{FEV}{ }_{1}$ is below $80 \%$ while the $\mathrm{FEV}_{1} / \mathrm{FVC}$ is above $70 \%$. High doses of VOCs in the ambient environment lead to the changes of the respiratory tract and lung function of a person ${ }^{18}$.

Previous studies by $\mathrm{CY}$ et al. ${ }^{26}$ and Saijo et al. ${ }^{27}$ found that VOCs concentration was associated with respiratory symptoms such as cough, nasal symptoms and respiratory problems among the 
industrial workers. But, the deterioration of the subjects' lung functions in this study was only associated with nasal symptoms and not with cough and dyspnea symptoms. BMI, smoking habits and working years did not show a significant association with lung function status of the exposed group. Research by Lin et al. ${ }^{28}$ and Zhou et al. ${ }^{29}$ also found no significant interaction on the exposure of VOCs pollutant in active smoker and non-smoker. Another study also found that BMI did not directly affect the lung function status of the workers ${ }^{30}$. Insignificant association results might be due to other confounding factors such as age and gender. Volume and lung capacity of the elderly are much lower compared to adult lung capacity. In the aspect of gender, male has larger lung capacity as compared to female ${ }^{31}$.

In this study, the deterioration of workers' lung functions might be associated with the VOCs concentration in the production area via general exposure. However, this study has some limitations. Further studies such as the personal exposure to target pollutants should be conducted to find the culprit that harms the respiratory health and other possible diseases.

\section{CONCLUSION}

In conclusion, the concentration of VOCs at the production area was higher compared to the office area. The results also showed a decline in the lung functions of the exposed group possibly due to higher level of VOCs concentrations. Therefore, the indoor air pollutants need to be monitored and controlled such as by using biofiltration to assure safe and healthy working environment for workers.

\section{Conflict of interest}

The authors declare no potential conflict of interest.

\section{Acknowledgment}

The authors gratefully acknowledge the workers of the transformer manufacturing plant for participating in this study and thank the laboratory assistant of Environmental Health \& Industrial Safety programme, Faculty of Health Sciences, UKM for the technical support.

\section{Funding}

This study was financially supported by

University Research Grant (GUP) Code: GUP-

2018-063 from Universiti Kebangsaan Malaysia.

\section{REFERENCES}

1. Levinson C. Definition of the Manufacturing Industry, 2018. https: / / bizfluent.com/facts-6853113definition-manufacturing-industry.html (accessed 5 March 2019).
2. Torén $\mathrm{K}$ \& Blanc PD. Asthma caused by occupational exposures is common - A systematic analysis of estimates of the population-attributable fraction, BMC Pulmonary Medicine 2009; 9(1):7-17.

3. Tarlo SM. Update on work-exacerbated asthma. International Journal of Occupational Medicine and Environmental Health 2015; 29(3): 369-374.

4. Lee, R. Impregnation, 2011. http://www.vias.org/eltransformers/lee _electronic_transformers_03_08.html (accessed 17 May 2019).

5. Jarnstorm H, Sareela K, Kalliokoski $P$, Pasanen AL. The Impact of Emissions from Structures on Indoor Air Concentrations in Newly Finished Buildings - Predicted and On-Site Measured Levels. Indoor and Built Environment 2008; 17(4): 313-323.

6. D'Amato G, Vitale C, De Martino A, Viegi G, Lanza M, Molino A, Sanduzzi A, et al. Effects on asthma and respiratory allergy of Climate change and air pollution. Multidisciplinary Respiratory Medicine 2015; 10(1): 39.

7. Arif $A A$, Shah SM. Association between personal exposure to volatile organic compounds and asthma among US adult population. International Archives of Occupational and Environmental Health 2007; 81(4): 711-719.

8. Zarogoulidis $\mathrm{P}$, Freitag $\mathrm{L}$, Besa $\mathrm{V}$, Teschler $\mathrm{H}$, Kurth I, Khan AM, Sommerwerck U, et al. Exhaled volatile organic compounds discriminate patients with chronic obstructive pulmonary disease from healthy subjects. International Journal of Chronic Obstructive Pulmonary Disease 2015; 10: 399-406.

9. Gong $\mathrm{Y}$, Wei $\mathrm{Y}$, Cheng J, Jiang $\mathrm{T}$, Chen $\mathrm{L}$, $\mathrm{Xu} B$. Health risk assessment and personal exposure to Volatile Organic Compounds (VOCs) in metro carriages - A case study in Shanghai, China. Science of the Total Environment 2017; 574:1432-1438.

10. United State Environmental Protection Agency (USEPA). Exposure Assessment Tools by Routes - Inhalation, 2018. https://www.epa.gov/expobox/exposure -assessment-tools-routes (accessed 30 May 2019).

11. Harbison SC, Johnson GT, McCluskey JD, Xu P, Mohammad S, Wolfson J, Harbison R. D. Occupational Health Surveillance: Pulmonary Function Testing in Utility 
Workers. Journal of Clinical Toxicology 2014; 5(006): 1-4.

12. Tsai, WT. Toxic Volatile Organic Compounds (VOCs) in the Atmospheric Environment: Regulatory Aspects and Monitoring in Japan and Korea. Environments 2016; 3(23): 1-7.

13. Statement of the American Thoracic Society. Standardization of spirometry: 1987 update. Am Rev Respir Dis 1987; 136:1285-1298.

14. Fenton ME, Graham BL, Stanojevic S, et al. Interpretation of spirometry in Saskatchewan first nations adults. Ann Amer Thoracic Soc 2018; 15(10): 1237-39.

15. Industrial Code of Practice on Indoor Air Quality (ICOP), 2010. https: / /www.dosh.gov.my/index.php/ch emical-management- $v$ /indoor-air-quality (accessed 10 May 2019).

16. Global Initiative for Chronic Obstructive Lung Disease (GOLD). Management and Prevention of Chronic Obstructive Pulmonary Disease 2013: 1-14.

17. Sarigiannis D, Karakitsios S, Gotti A, Papaloukas C, Kassomenos P, Pilidis G. Bayesian Algorithm Implementation in a Real Time Exposure Assessment Model on Benzene with Calculation of Associated Cancer Risks. Sensors 2009; 9(2): 731-755.

18. Kwon JW, Park HW, Kim WJ, Kim MG, Lee SJ. Exposure to volatile organic compounds and airway inflammation. Environmental Health: A Global Access Science Source 2018; 17(1): 1-8.

19. Zhong L, Su FC. Batterman S. Volatile Organic Compounds (VOCs) in Conventional and High Performance School Buildings in the U.S. International Journal of Environmental Research and Public Health 2017; 14(100): 1-18.

20. Cometto-Muñiz JE, Cain WS, Abraham MH. Detection of single and mixed VOCs by smell and by sensory irritation. Suppl 2004; 8: 108-117.

21. He Z, Li G, Chen J, Huang Y, An T, Zhang C. Pollution characteristics and health risk assessment of volatile organic compounds emitted from different plastic solid waste recycling workshops. Environment International 2015; 77: 85-94.

22. Lee SC, Chiu MY, Ho KF, Zou SC, Wang X. Volatile organic compounds (VOCs) in urban atmosphere of Hong Kong. Chemosphere 2002; 48(3): 375-382.
23. Nemer $M$, Kristensen $P$, Nijem $K$, Bjertness $E$, Skare $\varnothing$, Skogstad $M$. Lung function and respiratory symptoms among female hairdressers in Palestine: a 5-year prospective study. BMJ Open 2015; 5(10): 1-7.

24. Mehta JN, Gupta A, Bhatt K, and Vasani K. Pulmonary function in petrol pump workers in Anand district. National Journal of Physiology, Pharmacy, and Pharmacology 2018; 8(1): 23-7.

25. Prasetyo A, Darry S, Redyaksa D. et al. 2017. Occupational exposure on gasoline station workers not affect the nasal mucociliary clearance time and pulmonary function test. Advance Science Letters 2017; 23(4): 3406-8.

26. Lu CY, Ma YC, Lin JM, Li CY, Lin RS, Sung FC. Oxidative stress associated with indoor air pollution and sick building syndrome-related symptoms among office workers in Taiwan. Inhalation Toxicology 2007; 19(1): 57-65.

27. Saijo $Y$, Kishi $R$, Sat $F$, Katakura $Y$, Urashima Y, Hatakeyama A, Kobayashi S, et al. Symptoms in relation to chemicals and dampness in newly built dwellings. International Archives of Occupational and Environmental Health 2004; 77(7): 461-470.

28. Lin YS, Egeghy PP, Rappaport SM. Relationships between levels of volatile organic compounds in air and blood from the general population. Journal of Exposure Science and Environmental Epidemiology 2008; 18(4): 421-429.

29. Zhou $Y$, Sun $H$, Xie J, Song $Y$, Liu $Y$, Huang $X$, Zhou $T$, et al. Urinary Polycyclic Aromatic Hydrocarbon Metabolites and Altered Lung Function in Wuhan, China. American Journal of Respiratory and Critical Care Medicine 2016; 193(8): 835846.

30. Al Ghobain M. The effect of obesity on spirometry tests among healthy nonsmoking adults. BMC Pulmonary Medicine 2012; 12(10): 1-5.

31. Harik-Khana RI, Wiseb RA, Flega JL. The effect of gender on the relationship between body fat distribution and lung function. Journal of Clinical Epidemiology 2001; 54(4): 399-406. 